\title{
Alpha-feto protein negative hepatoid carcinoma of likely primary peritoneal origin: A case report and literature review
}

\author{
Kate Roberts ${ }^{1}$, J effrey Goh ${ }^{1,2}$, Touraj Taheri ${ }^{3}$ \\ 1. Medical Oncology Department, Royal Brisbane and Womens' Hospital, Brisbane, Australia. 2. University of Queensland, \\ Brisbane, Australia. 3. Pathology Department, Royal Brisbane and Womens' Hospital, Brisbane, Australia.
}

Correspondence: Kate Roberts, MBBS. Address: Medical Oncology Department, Royal Brisbane and Womens' Hospital, Herston, Queensland, Australia. E-mail: katee.roberts@gmail.com

Received: July 16, 2015

DOI : $10.5430 /$ crcp.v2n4p84
Accepted: September 8, 2015

URL: http://dx.doi.org/10.5430/crcp.v2n4p84

\section{Abstract}

Hepatoid carcinoma is a rare tumour, most commonly arising from the stomach. It is usually associated with an elevated serum alpha-feto protein (AFP). This article aims to (i) discuss the first published case of an alpha-feto protein negative hepatoid carcinoma most likely arising from the peritoneum, (ii) present a brief literature review on hepatoid carcinomas, (iii) discuss differential diagnoses for the case, and (iv) discuss management options.

\section{Key words}

Hepatoid, Primary peritoneal, Alpha-feto protein, HepPar-1

\section{I ntroduction}

Hepatoid carcinoma is a rare tumour with an aggressive clinical picture. It most commonly arises from the stomach, but has also been identified in the gallbladder, colon, lung, genitourinary tract and gynaecological organs ${ }^{[1]}$. It is known to metastasise early to lymph nodes, liver and lung, and has a poor prognosis ${ }^{[2]}$. One-year survival rates are estimated at $52 \%{ }^{[3]}$. The histology of hepatoid carcinoma closely resembles that of hepatocellular carcinoma, and therefore can pose a difficult diagnostic dilemma. Like hepatocellular carcinoma, hepatoid carcinoma is usually associated with a raised serum alpha-feto protein AFP ${ }^{[2]}$, but a number of cases have now been reported with normal AFP levels ${ }^{[3,4]}$.

\section{Case presentations}

A 71-year-old female, presented with five months of abdominal bloating and non-specific abdominal pain. The patient had a background history of left ovarian granulosa cell tumour in 1987, which was removed surgically during a total hysterectomy and left salpingo-oopherectomy. No further treatment was required. She also had paroxysmal atrial fibrillation, anxiety and was a current smoker with a 15 pack-year history. Large volume ascites was found on initial presentation, and the patient underwent abdominal paracentesis, with $12 \mathrm{~L}$ of fluid drained. Cytology did not reveal malignancy. 
A CT abdomen and pelvis was performed after ascitic drainage, which revealed soft tissue infiltration of the omentum and small bowel mesentery, and extensive residual fluid. There were no mass lesions within the liver. CA125 was elevated at $354 \mathrm{kU} / \mathrm{L}$. Inhibin B level was < $10 \mathrm{ng} / \mathrm{L}$. CEA and CA19.9 were normal, at $4.9 \mu \mathrm{g} / \mathrm{L}$ and $13 \mathrm{kU} / \mathrm{L}$ respectively. The patient underwent diagnostic laparoscopy, which showed extensive omental and peritoneal disease, with $5 \mathrm{~mm}-10 \mathrm{~mm}$ nodules deposited over the right diaphragm, anterior abdominal wall, pelvis and rectal surface. No ovarian masses were seen. Initial report from the pathologists on the omental biopsy excluded recurrent granulosa cell tumour, and recommended treatment for malignancy of unknown primary. The patient was commenced on carboplatin (AUC5) and paclitaxel $\left(175 \mathrm{mg} / \mathrm{m}^{2}\right)$ q3 weekly.

CT chest identified a $3 \mathrm{~cm}$ right lower lobar mass, with probable extension into the bronchus, suggestive of a synchronous lung primary. There were moderate emphysematous changes throughout the lungs. Bronchoscopy was performed to obtain a biopsy from the lung mass. Further review of the omental biopsy revealed a poorly differentiated metastatic carcinoma with hepatoid morphology (see Figure 1A). Immunostaining was suggestive of metastatic hepatocellular carcinoma or hepatoid carcinoma. Tumour cells were positive for: CK8/18, MNF116, CK7 (patchy), CA125, CEA and a strong reaction with HepPar1 (see Figure 1B). INI-1 was intact. Tumour cells were negative for AFP, inhibin, calretinin, CK20, ER, WT1, S100, CD10 and TTF-1.

Biopsy of the right lower lobar lesion performed via bronchoscopy identified the lesion as a likely metastatic deposit rather than a synchronous primary. Histology showed malignant cells which were CK7/CA125 positive, and CK20/TTF-1 negative. A PET scan was performed, but unfortunately there was low FDG uptake by the tumour after the patient's recent chemotherapy, and the findings were extremely non-specific. No obvious site of primary disease was identified.

Unfortunately the patient was noted to experience sudden onset dyspnoea and oxygen desaturations five days post chemotherapy, and was diagnosed with a right-sided pulmonary embolism, pleural effusions, and worsening ascites. Therapeutic Enoxaparin was commenced. A repeat CA125 performed one week after chemotherapy was $998 \mathrm{kU} / \mathrm{L}$. Over the next 72 hours, the patient continued to experience low oxygen saturations and increased work of breathing. Unfortunately, the patient developed severe respiratory failure, and CXR showed complete collapse and consolidation of the right lung. The patient was palliated, and was declared deceased later that day.

Figure 1. (A) H\&E stain $\times 200$ : Neoplastic epithelioid cells with hepatoid and rhabdoid appearance infiltrating the peritoneal fat. (B) HepPar1 Immunohistochemistry staining shows strong cytoplasmic positivity for this marker.

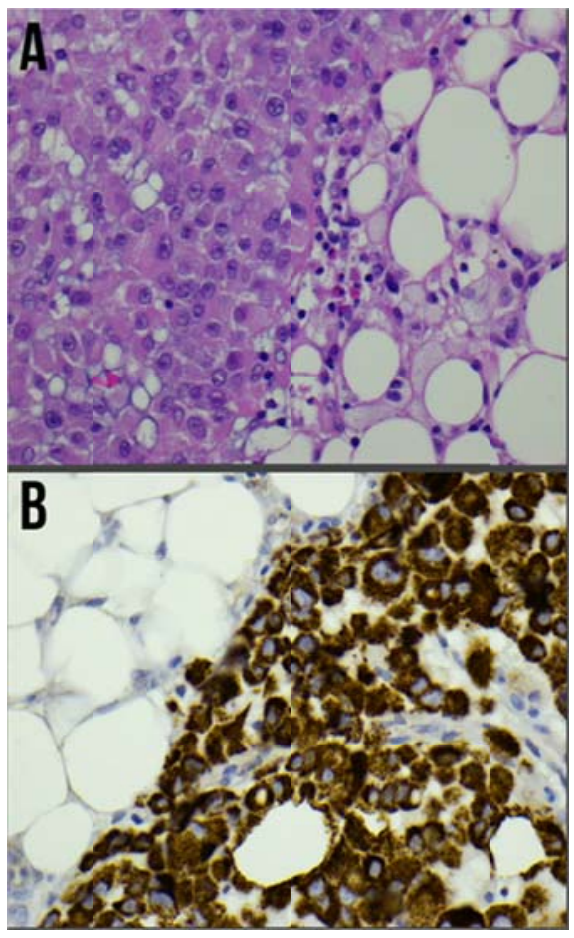




\section{Discussion}

Our case report describes a tumour with hepatoid morphology, and immunohistochemistry in keeping with either a hepatocellular carcinoma or hepatoid carcinoma. The convincing immunohistochemistry findings included a strong HepPar-1 positivity. There was, however, an unusual finding of both negative staining for AFP within the tumour and a normal serum AFP. The patient in our case report did not have a hepatic lesion identified on computed tomography, which makes a diagnosis of hepatocellular carcinoma less likely. The clinical picture at diagnosis, in combination with the available histopathology, a significantly raised CA125 and the absence of other raised tumour markers or an ovarian mass, makes the primary origin of this tumour to most likely be primary peritoneal. Primary peritoneal hepatoid carcinoma is very rare, with one review of 217 cases reporting the incidence of hepatoid carcinomas arising in the peritoneum as $0.9 \%{ }^{[3]}$. A diagnosis of likely primary peritoneal hepatoid carcinoma makes this case particularly unique, as this is the first reported case of AFP negative primary peritoneal hepatoid carcinoma, to our knowledge.

Morphologically, hepatoid carcinoma is similar in appearances to hepatocellular carcinoma, with tumour cells comprising of abundant eosinophilic cytoplasm, distinct cell borders and prominent nucleoli ${ }^{[5]}$. There are often frequent mitoses, and necrotic areas ${ }^{[6]}$. They usually stain positive for the epithelial markers CK8, CK18 and CK19, but CK7 and CK20 staining is variable ${ }^{[1,3]}$. HepPar1 has been reported as the most sensitive and specific marker for HCC, but has also been documented in nearly $40 \%$ of hepatoid carcinomas ${ }^{[3]}$, and is also present in hepatoid yolk sac tumours and gastric carcinomas. Polyclonal CEA with membranous staining is also commonly immune-reactive in hepatoid carcinoma ${ }^{[1]}$. Glypican 3 staining has been found to be positive in $100 \%$ of cases ${ }^{[7]}$, and a high proportion is positive for AE1/AE3 (92.3\%) and alpha-1-antitrypsin stain $(91 \%){ }^{[7]}$. It is extremely difficult to differentiate hepatoid carcinoma from a diagnosis of hepatocellular carcinoma, with the exception of clinical identification of a hepatic tumour ${ }^{[1]}$.

The other major differential usually considered in a case of hepatoid carcinoma is hepatoid yolk sac tumour (HYST), which is also an AFP-producing malignancy. HYST more commonly presents in younger patients (mean age 22 years) and is often associated with gonadal dysgenesis ${ }^{[8]}$. HYST is typically HepPar1 negative and has only focal staining for pCEA $^{[2,5]}$. Therefore, the clinical and immuno-histochemical findings of our case study are not in keeping with a HYST.

The main differential for this case would be hepatoid carcinoma of another origin, particularly gastrointestinal, due to the known higher incidence of a gastrointestinal primary site. It would have been ideal to have completed our search for a primary site, with both endoscopy and colonoscopy, but the patient deteriorated prior to this being performed. Although it is not a specific marker, the elevated CA125 of $>900 \mathrm{kU} / \mathrm{L}$ suggests an ovarian or peritoneal source. The patient's clinical presentation also corresponds with this diagnosis.

Imaging may also play a role in ascertaining the alternative diagnosis of hepatocellular carcinoma, or the primary origin of a metastatic hepatoid carcinoma. On computed tomography, hepatoid carcinoma may present as a heterogeneously enhancing mass ${ }^{[9]}$. Both computed tomography and magnetic resonance imaging play a crucial role in the detection of a possible hepatocellular primary ${ }^{[10]}$. Single case reports of the use of FDG PET/CT imaging have revealed promising results for assisting with the diagnosis and staging of hepatoid tumours ${ }^{[11-13]}$.

Other differentials include endometrial carcinoma, and clear-cell carcinoma, lipid cell tumour and undifferentiated carcinoma ${ }^{[5]}$. The other differential to consider in this case is recurrent granulosa cell tumour. This is usually a welldifferentiated, unilateral tumour, presenting with a median age of 52 years ${ }^{[14]}$. It is often associated with a raised serum inhibin level. Cell-exner bodies are found in $30 \%-50 \%$ of tumours ${ }^{[14]}$. The tumour reported in this case had a normal serum inhibin, negative tumour staining for inhibin, and the additional immunohistochemistry was not consistent with recurrent granulosa cell tumour.

Our patient initially commenced treatment for a carcinoma of unknown primary, with carboplatin and paclitaxel. Due to the paucity of data, there is no established treatment for hepatoid carcinoma, particularly of peritoneal origin. Treatment 
regimen for hepatoid carcinoma is usually consistent with regimens for the primary site of the cancer ${ }^{[6,15]}$. A number of case reports have included the use of sorafenib, a multi-target tyrosine kinase inhibitor ${ }^{[16,17]}$ due to its success in hepatocellular carcinoma, with variable results. A single case of metastatic pancreatic hepatoid carcinoma treated with sorafenib resulted in 7 months of progression-free survival ${ }^{[16]}$. A single case of hepatoid carcinoma of the ovary reported by Campos et al. ${ }^{[18]}$, discussed the use of hyperthermic intraoperative intraperitoneal chemotherapy (HIPEC) using paclitaxel, in a patient whom presented with omental caking from ovarian hepatoid adenocarcinoma. The HIPEC was given after cytoreductive surgery, and was followed by six cycles of carboplatin (AUC6) and paclitaxel (175 mg/ $\mathrm{m}^{2}$ ). After 28 months of follow-up, the patient had a single vertebral metastasis, but no peritoneal recurrence.

Quality evidence on the treatment of hepatoid carcinomas, particularly of ovarian or peritoneal origin is significantly lacking, and currently there are no registered clinical trials supporting further research into this area. Oncologists worldwide need to pool their experiences in this area to provide much-needed advances in the treatment of these rare and aggressive tumours.

\section{Conflicts of interest}

No relevant disclosures or conflicts of interest.

\section{References}

[1] Terracciano L, Glatz K, Mhawech P, et al. Hepatoid Adenocarcinoma With Liver Metastasis Mimicking Hepatocellular Carcinoma. An Immunohistochemical and Molecular Study of Eight Cases. Americal Journal of Surgical Pathology. 2003; 27(10): 1302-12. http://dx.doi.org/10.1097/00000478-200310000-00002

[2] Pandey M, Truica C. Hepatoid Carcinoma of the Ovary. Journal of Clinical Oncology. 2011; 29(15): 446-8. PMid: 21422440. http://dx.doi.org/10.1200/JCO.2010.33.6321

[3] Su J, Chen Y, Wang R, et al. Clinicopathological characteristics in the differential diagnosis of hepatoid adenocarcinoma: A literature review. World Journal of Gastroenterology. 2013; 19(3): 321-7. PMid: 23372352. http://dx.doi.org/10.3748/wjg.v19.i3.321

[4] Supriatna Y, Kishimoto T, Uno T, et al. Evidence for hepatocellular differentiation in alpha-fetoprotein-negative gastric adenocarcinoma with hepatoid morphology: a study with in situ hybridisation for albumin mRNA. Pathology. 2005; 37(3): 211-5. PMid: 16175893. http://dx.doi.org/10.1080/00313020500099221

[5] Sung J, Kim T, Park H, et al. Hepatoid carcinoma of the ovary without staining for alpha-fetoprotein. Obstetrics and Gynecology Science. 2013; 56(1): 41-4. PMid: 24327979. http://dx.doi.org/10.5468/OGS.2013.56.1.41

[6] Wang L, Zhong Y, Sun L, et al. Clinical and pathological features of hepatoid carcinoma of the ovary. World Journal of Surgical Oncology. 2013; 11: 29. PMid: 23363542. http://dx.doi.org/10.1186/1477-7819-11-29

[7] Su J-S, Chen Y-T, Wang R-C, et al. Clinicopathological characteristics in the differential diagnosis of hepatoid adenocarcinoma: a literature review. World Journal of Gastroenterology: WJG. 2013; 19(3): 321-7. PMid: 23372352. http://dx.doi.org/10.3748/wjg.v19.i3.321

[8] Ishikura H, Scully R. Hepatoid Carcinoma of the Ovary. A Newly Described Tumour. Cancer. 1987; 60: $2775-84$. http://dx.doi.org/10.1002/1097-0142(19871201)60:11<2775::AID-CNCR2820601130>3.0.CO;2-S

[9] Ren A, Cai F, Shang Y-N, et al. Gastric hepatoid adenocarcinoma: a computed tomography report of six cases. World Journal of Gastroenterology: WJG. 2014; 20(40): 15001-6. PMid: 25356063. http://dx.doi.org/10.3748/wjg.v20.i40.15001

[10] Tang A, Valasek MA, Sirlin CB. Update on the Liver Imaging Reporting and Data System: What the Pathologist Needs to Know. Advances in Anatomic Pathology. 2015; 22(5): 314-22. PMid: 26262514. http://dx.doi.org/10.1097/PAP.0000000000000089

[11] Seo HJ, Chung J-K, Go H, et al. A hepatoid adenocarcinoma of the stomach evaluated with (18) F-FDG PET/CT: intense (18) F-FDG uptake contrary to the previous report. Clinical Nuclear Medicine. 2014; 39(5): 442-5. PMid: 24152637. http://dx.doi.org/10.1097/RLU.0000000000000275

[12] Malya FU, Bozkurt S, Hasbahceci M, et al. A rare tumor in a patient with hepatic hydatic cyst: adrenal hepatoid adenocarcinoma. Case Reports in Medicine. 2014; 2014: 824574. PMid: 24715921. http://dx.doi.org/10.1155/2014/824574

[13] Sun X, Li Y, Dong M, et al. Hepatoid adenocarcinoma of the stomach: dual-time-point (18) F-FDG PET/CT findings. Japanese Journal of Radiology. 2014; 32(12): 721-4. PMid: 25287326. http://dx.doi.org/10.1007/s11604-014-0366-1 
[14] Geetha P, Nair M. Granulosa cell tumours of the ovary. Australian and New Zealand Journal of Obstetrics and Gynaecology. 2010; 50: 216-20. PMid: 20618236. http://dx.doi.org/10.1111/j.1479-828X.2010.01154.x

[15] Ye M-F, Tao F, Liu F, et al. Hepatoid adenocarcinoma of the stomach: a report of three cases. World Journal of Gastroenterology: WJG. 2013; 19(27): 4437-42. PMid: 23885160. http://dx.doi.org/10.3748/wjg.v19.i27.4437

[16] Petrelli F, Ghilardi M, Colombo S, et al. A rare case of metastatic pancreatic hepatoid carcinoma treated with sorafenib. Journal of Gastrointestinal Cancer. 2012; 43(1): 97-102. PMid: 21365478. http://dx.doi.org/10.1007/s12029-011-9264-2

[17] Gavrancic T, Park Y-HA. A novel approach using sorafenib in alpha fetoprotein-producing hepatoid adenocarcinoma of the lung. Journal of the National Comprehensive Cancer Network: JNCCN. 2015; 13(4): 387-91. PMid: 25870375.

[18] Cascales Campos PA, Gil Martinez J, Torroba A, et al. Peritoneal dissemination of hepatoid carcinoma of the ovary treated with cytoreductive surgery and hyperthermic intraoperative intraperitoneal chemotherapy. Case Reports in Medicine. 2013; 2013: 283295. PMid: 23840218. http://dx.doi.org/10.1155/2013/283295 